\title{
A STUDY ON APPLICATION OF BLOCKCHAIN TECHNOLOGY TO CONTROL COUNTERFEIT DRUGS, ENHANCE DATA PRIVACY AND IMPROVE DISTRIBUTION IN ONLINE PHARMACY
}

\author{
Deepnshu Singh, Jyotinder Kaur Chaddah \\ Guru Nanak Institute of Management Studies, Mumbai, Maharashtra, India
}

Correspondence:jyotinder@gnims.com

\begin{abstract}
Technology has always emerged to embolden the existing working process. On the one hand, it encourages transparency, accessibility and robustness in the system and on the other hand, it begets mitigation of the risks and allows us to detect, evaluate and eliminate vulnerability in the system. The most prominent technologies in todays' world like Artificial Intelligence, Virtual/Augmented Reality, Automation, Cloud Computing are thriving to solve society's problems and ensure the expedition in the process from its previous generation.
\end{abstract}

Blockchain technology is no exception in providing the solution to eliminate the counterfeit markets across the globe and building trust among parties to do business without the fear of indulging or facing any unscrupulous business.

Blockchain technology can ensure data privacy while improving supply chain transparency and reducing fraud. It can provide all stakeholders within a certain supply chain with access to the same information, potentially reducing errors. A decentralised application can pave the way to promulgate online pharmaceutical business where health information and each stakeholders' data is not compromised. Against this backdrop the research conducted throws light on the challenges in the online medical drug and devices' distribution and proposes a solution, an architectural design for blockchain technology in an online pharmaceutical platform to mitigate the counterfeit market while bringing efficiency to the ecosystem.

\section{KEYWORDS}

Blockchain, Counterfeit Drugs, Decentralised, Permissioned Consensus Algorithm

\section{INTRODUCTION}

Blockchain technology is successful in offering a formidable solution to curb the counterfeit markets across the globe. It is simultaneously building confidence among stakeholders to do business without the fear of any devious business transactions.
Today, the penetration of online pharmacies is supported by easy availability of the internet, the rapid shift towards self-assessment due to improved doctor-patient relations and medical technologies, improved consumer experience in online purchases, sales across the length and breadth of India are among many important factors. 
The access-supply-reach of medicines is thriving due to different successful and unique business models across India in particular and the world in general.

Against this backdrop, this study throws light on the challenges in the online medical drug and devices' distribution and proposes a solution to mitigate the counterfeit market while bringing efficiency to the environment.

Further, the survey is conducted among consumers in Maharashtra because of high internet penetration, affordable smart devices, dense population and better reachability. It is proven that blockchain technology can ensure data privacy without compromising on supply chain transparency and reducing fraud. It is helpful in reducing errors while providing stakeholders in a certain network access to the same real time information.

According to the data [1] India stands at 3rd Rank in the global pharmaceutical industry by capacity and $14^{\text {th }}$ rank in terms of value. This makes India among the nations to ensure equity and inclusion for all in the supply and distribution of medical devices and drugs across the globe. However, these unprecedented times have unearthed the need for advanced technological incorporation in the healthcare sector. India with 3000 drug companies and nearly 10,500 manufacturing units positions itself in leading its scientific approach to ensure 5As namely availability, accessibility, affordability, awareness and accountability.

Also, the burgeoning pharmaceutical sector is projected to grow at US\$ 100 Billion and the medical devices business is pegged at US $\$ 25$ Billion by 2025 . The Government of India's progressive policy also acts as an impetus to attracting Foreign Direct Investment (FDI) in the pharmaceutical sector with US\$16.45 Billion (April 2000 \& June 2020) and there is an increase in Govt. expenditure in this sector (1.6\% of GDP) in 2020.

Still, major impediments in the healthcare sector are the growth of the counterfeit drugs market; Where $75 \%$ of counterfeit drugs supplied to the world over have origins in India, which emerge as a hurdle to the global supply chain of drugs.

\section{PURPOSE OF STUDY}

This work is an attempt to design and envisage blockchain technology in the online pharmaceutical industry by designing a proof of concept to conceptualise the working and its supply chain distribution across different channels.

\section{METHODOLOGY}

A survey has been conducted using Google Forms to study the consumer perception and experience in purchasing online drugs and medical devices. Data analysis (Correlation) has been performed on the responses collected from 3 cities i.e., Mumbai, Nagpur and Pune using IBM Statistical Package for the Social Sciences. Descriptive exploratory research has been conducted.

The researcher while accessing the secondary data excluded the data which was not relevant to the objective and questionnaire. The appropriateness of data was judged in light of the nature and scope of the topic investigated. The researcher evaluated the reliability of the data. Dochartaigh [2] refers to evaluating the reputation of the source. Gupta [3] emphasized that sample selection and data collection are interwoven, and one has an impact on the other.

Invariably financial growth, education and IT grow parallel. This explains the reason why Cities in Maharashtra were chosen for study because in it nests the financial capital of India i.e., Mumbai Further Pune which is also known as Oxford of the East has a growing industrial hinterland, with IT, Engineering and allied companies sprouting. And Nagpur is the third-largest city in Maharashtra. Therefore, respondents residing in these cities are well versed with online purchase of pharmaceuticals drugs and devices.

\section{THE OBJECTIVE OF THE STUDY:}

To Determine ways to counter counterfeit products, distribution plan and the concerns of data privacy in the online Pharmacy domain. 
This study aims to consider the customer's preferences regarding purchasing medical drugs online and incorporating blockchain technology as the solution to mitigate the cumbersome process while bringing transparency to the overall ecosystem. The researcher is proposing a comprehensive plan that can add an extra layer of security for the online transaction of pharmacy purchases.

\section{LITERATURE REVIEW:}

Blockchain [4] has demonstrated its ability to transform the outmoded supply chain network into a safe, automated and decentralized supply chain. In blockchain technology the entire transaction can be observed with more clarity. [5] The key to success is data privacy, distribution and ensuring genuine drugs reach the customers.

Risks in the supply chain of pharmaceutical companies have been documented. [6] Some of the challenges faced by online pharmaceutical platforms included data security and secure financial transactions. [7]

The issue of counterfeit drugs and emphasised the importance of addressing it to safeguard patient's faith in the benefits of pharmaceuticals have been highlighted. [8]

There is an increase in counterfeit drug supply and availability in India. There is a high demand for counterfeit products in the Indian market which needs to be curtailed. [9]

Another aspect covered by Chakraborty and Satsangi [10] is that the factors leading to the demand for ePharmacy in India are mainly because of unsatisfied medical needs due to the larger population and increased usage of the Internet. As consumer behaviour in India is fast changing, there is a huge demand to access a wide range of products at the click of a computer, and competitive prices. Attitude emerges as an important predictor of counterfeit product.[11]

Pharmaceutical companies should have a novel approach to reduce counterfeiting of pharmaceutical products. [12] Here blockchain and other relevant technologies can be utilised. Consumer engagement and education is important to curb counterfeiting and dispelling incorrect information regarding data privacy.
The importance of consumer awareness regarding identification of genuine sites is stressed [13] is in addition to the desire to curb fraudulent practices like data privacy and supply chain issues. [14]

Guidelines for standardizing smartphone-based healthcare applications to integrate with hospital information system such as electronic medical record and patient monitoring systems to maximize the power of mobile applications are emphasised. [15] adding that counterfeiting brings new challenges to brand management.

Others have proposed a mobile healthcare system based on Android and Web applications. [16] The system offers medical assistance to patients and saves time and mobility. The applications allow patients to make appointments with doctors and assigns reminders for the prescribed medications and vaccinations.

\section{EMPIRICAL AND THEORETICAL RESULTS:}

Reliability test has been conducted on the survey questionnaire using IBM SPSS which resulted in $78 \%$. Therefore, the extracted value is higher than the standard value which concludes that the questionnaire is reliable [Table 1].

\section{TABLE 1: RELIABILITY STATISTICS}

\section{Reliability Statistics}

\begin{tabular}{r|r}
$\begin{array}{c}\text { Cronbach's } \\
\text { Alpha }^{\mathrm{a}}\end{array}$ & $\mathrm{N}$ of Items \\
\hline .780 & 14 \\
\hline
\end{tabular}

Responses were collected from 3 cities i.e., 72\% from Mumbai, $16 \%$ from Nagpur and 12\% from Pune [Fig. 1]. Male participants contributed $59 \%$ and the female contribution to the study was $41 \%$ (28[Fig.2] with the majority of respondents being a student (73\%) and the rest were an employee (27\%) [Fig.3]. The major reason for the active participation of female respondents can be the increase in literacy ratio, awareness among the female population, access to smartphones and the digital world. 
PURCHASING BEHAVIOUR

FIG.4 PURCHASING BEHAVIOUR

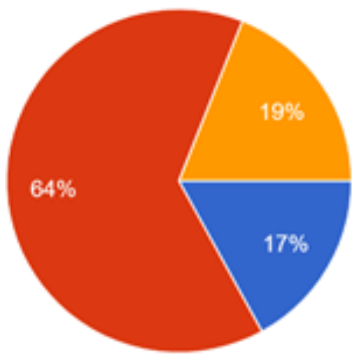

Weekly

Monthly

Yearly

The majority of the participants mostly ordered medicines every month $64 \%$ while $17 \%$ were weekly visitors and $19 \%$ were annual visitors. Buyers tend to prefer to purchase their medicines in advance for a month to avoid visiting the store or website often.

\section{MEDICAL DRUGS/DEVICES BOUGHT ONLINE}

\section{FIG.5 PLATFORM SELECTION}

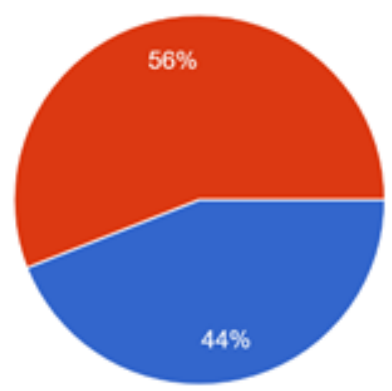

Almost half $(56 \%)$ of the total participants used an online platform to buy medical drugs/devices online and the rest (44\%) never bought medical drugs/devices online [Fig. 5].

FIG.6 BUDGET

What is the budget that you prefer while buying medical drugs/devices online?

70 responses

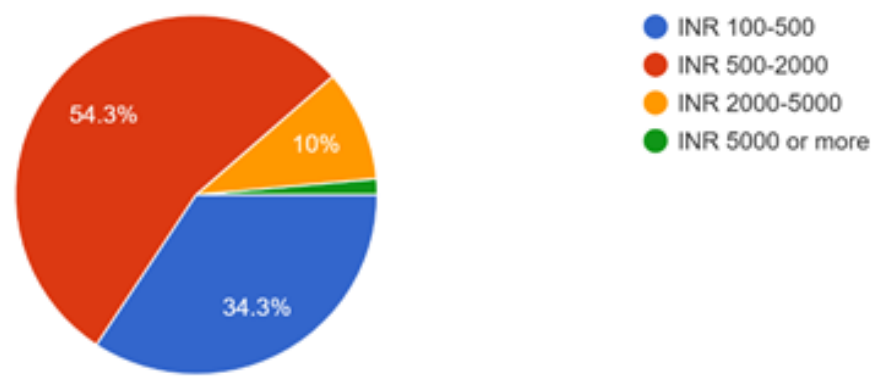

The budget at which the participants purchased online products were INR 100-500 (34\%), INR 500-2000 (54\%) \& INR 2000-5000 (10\%) [Fig. 6].

\section{FIG.7 DATA PRIVACY}

Do you feel threatened about data privacy while shopping online?

70 responses

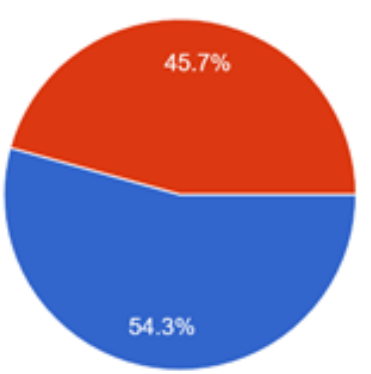

Yes No

Concerns regarding data privacy still being the impediments for the customers while purchasing medical drugs/devices online (54.3\%) [Fig. 7]

\section{FIG.8 COUNTERFEIT PRODUCTS DELIVERY}

Do you feel concerned about the counterfeit goods being delivered?

70 responses
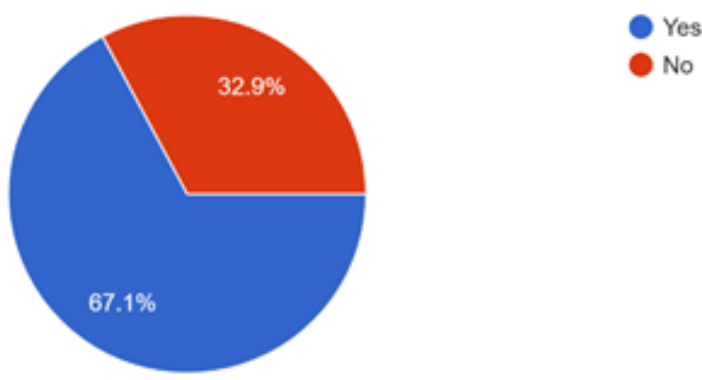

No

\section{FIG.9 AFFORDABLE HEALTHCARE SERVICES}

Do you feel online health services can help in providing affordable healthcare in India?

70 responses

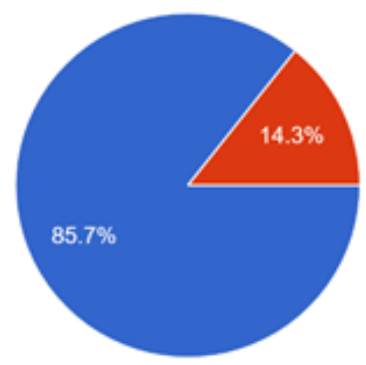

Yes No 
FIG.10 CONSTRAINTS OF PURCHASING MEDICAL

\section{DRUG\&/DEVICES ONLINE}

Which are the major consitraints that you feel while shopping for medical products online?

70 responses

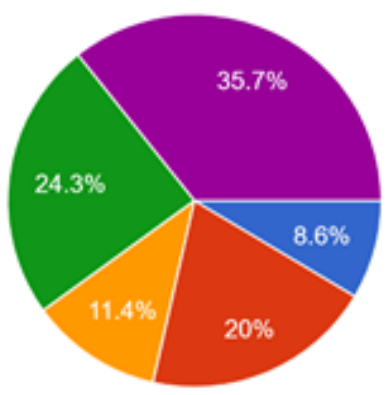

Pearson Correlation test helped in understanding the relationships between online customers, counterfeit products being delivered, online health services for affordable healthcare, customer satisfaction with the services provided by the online pharmaceutical delivery platforms. Customer satisfaction from online delivery services was more strongly related to the online consumers, $r$ (99) $=.73, p<0.01$, affordable healthcare through online health services were also strongly related to the online consumers, $\mathrm{r}(99)=.53, \mathrm{p}<0.01$ and counterfeit products delivery experiences also showed strong relation to the online consumers, $r(99)=.29, p<$ 0.01 [Table 2].

TABLE 2: CORRELATION: ONLINE MEDICAL DRUGS/DEVICES DELIVERY EXPERIENCES

\begin{tabular}{|l|l|l|l|l|}
\hline & $\begin{array}{l}\text { Online } \\
\text { Consumers }\end{array}$ & $\begin{array}{l}\text { Counterfeit } \\
\text { Products } \\
\text { Experiences }\end{array}$ & $\begin{array}{l}\text { Affordable Healthcare } \\
\text { through Online Health } \\
\text { Services }\end{array}$ & $\begin{array}{l}\text { Customer Satisfaction } \\
\text { towards the Online Health } \\
\text { Services }\end{array}$ \\
\hline $\begin{array}{l}\text { Pearson Correlation } \\
\text { Sig. (2-tailed) }\end{array}$ & 1 & $\begin{array}{l}.295^{* *} \\
.003\end{array}$ & $.533^{* *}$ \\
.000 & .000 \\
\hline
\end{tabular}

- Following is the Architectural design for blockchain technology as presented by the Researcher

FIG.11 WORKING ARCHITECTURE OF BLOCKCHAIN TECHNOLOGY

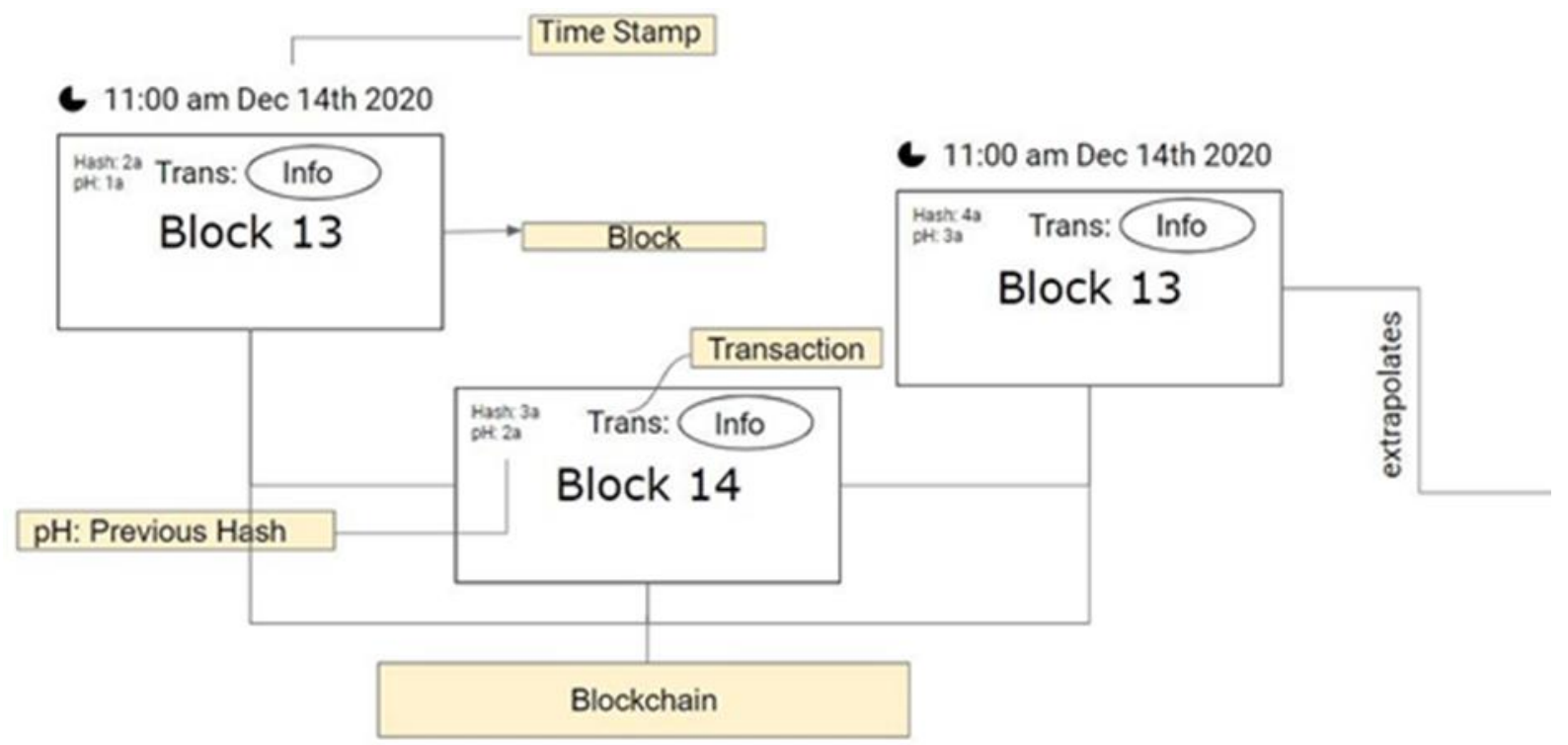


Set of blocks are tied with each other sharing a network which are decentralized in nature. A series of numbers and letters in a block are converted into an encrypted code also known as Hash which is followed by Previous Hash $(\mathrm{pH})$ observed on the subsequent block. Any activity performed in a block result into a transaction which contains protected information. As the activity are observed in any block, a timeline info is stamped to that block that makes this technology unalterable.

- $\quad$ Following is the proposed architectural design for Blockchain Technology (Permissioned) in Online Pharmaceutical platform:

\section{FIG.12 WORKING ARCHITECTURE OF PERMISSIONED BLOCKCHAIN IN ONLINE PHARMACEUTICAL PLATFORM}

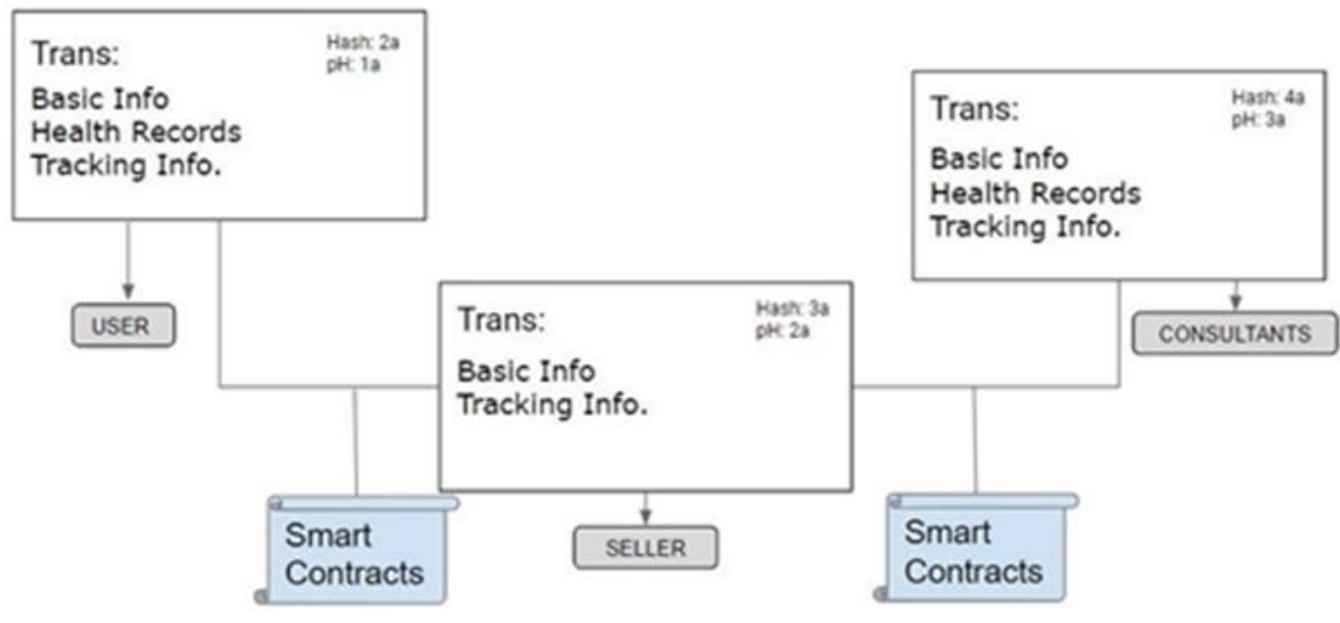

Permissioned Blockchain can be successfully used in any scenario where two or more parties are involved in an agreement to streamline the workflow of their businesses. These agreements are shared among the user, drug distributor and physician for a conclusive outcome and ensuring their shared interests. Once the agreement has been made, these can be formulated into codes that helps in building Smart Contract among the parties to avoid any discrepancies.

The above diagram illustrates the smart contracts been made between user, seller and the consultant which limits the access of information for seller and consultants. As the user's basic and tracking info are being shared with the seller but the seller does not have the access to user's electronic medical records (EMR). Although the EMR can be accessed by consultant as the contract has been established accordingly.

- $\quad$ Following is the proposed supply-chain distribution of online pharmacy application using blockchain technology (Permissioned);

FIG.13 DRUG \& MEDICAL DEVICES SUPPLY CHAIN DISTRIBUTION USING BLOCKCHAIN TECHNOLOGY

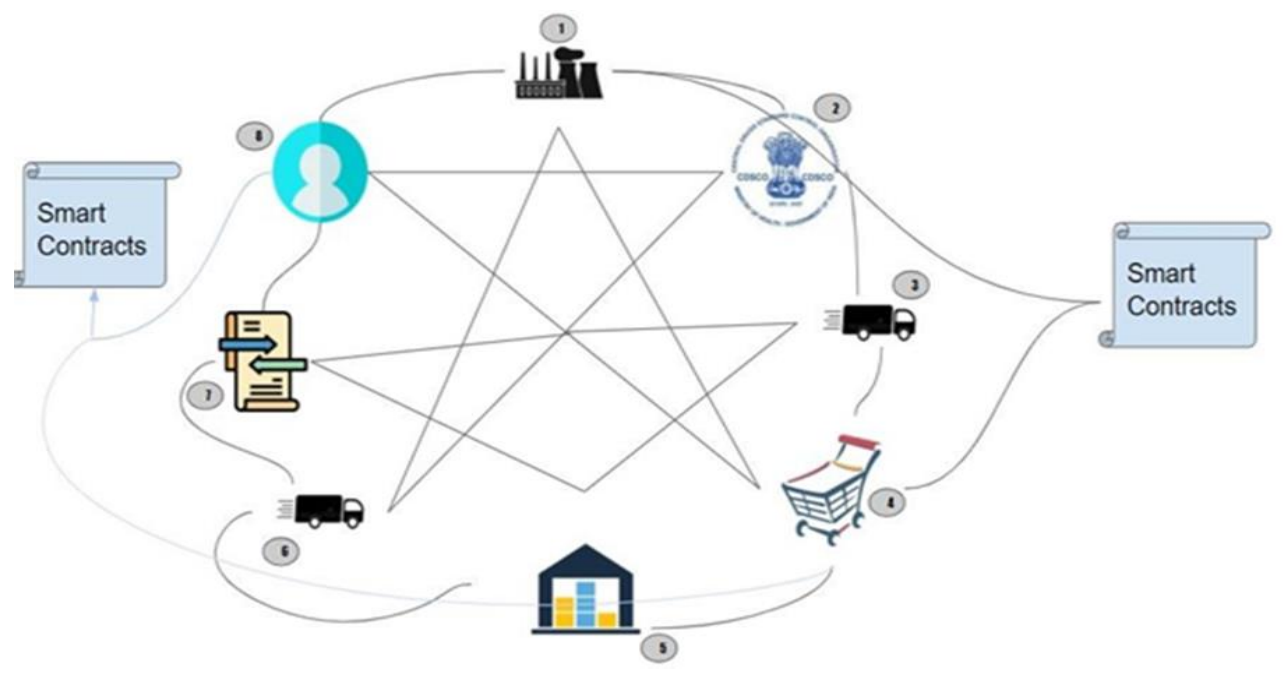


COMPONENTS OF SUPPLY CHAIN

\section{DISTRIBUTION}

1. Manufacturing

2. Inspection

3. Shipping

4. Seller

5. Warehouse

6. Shipping

7. Billing

8. User

The comprehensive supply chain distribution displayed in Fig. 13 shows the interrelationship among every stage of the supply which ensures an efficient and reliable approach at end-to-end delivery of medical products. All the nodes in the supply chain network have the ability to timely track the progress of each process through which every party in the transaction is aware and that puts the onus of the decisions on the party itself. Blockchain technology also enables the distributed ledger which mitigates the chances of any unscrupulous or delayed payment for any particular transaction. All the parties had entered into a smart contract, thus avoiding delays and allowing smooth business transactions. The end-user can track every transaction and hence enables him to know the origin of the product that ultimately avoids any chances of getting counterfeit goods.

\section{MANAGERIAL IMPLICATIONS}

The application designed on blockchain architecture requires miners to run the application efficiently. Some unique features such as application interoperability, robustness, intuitive and customizable will produce the best application in the market.

With the public-private partnership, this application can strengthen data privacy, mitigate the drug counterfeit market and bring efficiency in overall supply chain distribution of medical supplies. Here, the start-up can play a vital role in publishing such applications on the internet which will create a large-scale implementation in the area of innovation.

\section{DISCUSSIONS}

The platform must ensure to improve its efficiency and focus on bringing transparency to its processes. Thus, demand for such technology can be generated in the market resulting in higher acceptance among its users. Payment Transactions can be incorporated to this platform that will streamline the entire process in the application. Such payments made through this platform are a best way to reduce the loading time and accelerate the efficiency in the back-end operations.

\section{CONCLUSION}

Concerns over counterfeit products need to be addressed as this impacts the trust among users for purchasing medicines and medical devices online. Increasing impediments for the growth of an online business can be mitigated with the help of blockchain technology. Data privacy is a critical issue for the user, and this must be ensured by protecting the data from unauthorized parties.

Online purchases have been able to provide convenient and satisfactory services to consumers. Online healthcare services can be a panacea to India's major issues about providing affordable healthcare services to every citizen. Product quality and delivery time needs to be taken into consideration for improving the standard of online delivery of medical products.

\section{References}

1. https://www.ibef.org/industry/pharmaceuticalindia.aspx Accessed on 21 st May2021

2. Dochartaigh NO The Internet Research Handbook: A practical guide for students and researchers in the social sciences. London: Sage Publishing 2002

3. Gupta S P. Statistical Methods Reprint Sultan Chand and Sons;2005

4. Jamil, LH, KyuHyung.K, DoHyeun.K. A Novel Medical Blockchain Model for Drug Supply Chain Integrity Management in a Smart Hospital.2019

5. John W and Dr Azam MK. Distribution Structure in Indian Pharmaceutical Industry: Significance of Customer Relationship Management (CRM) and Distributor Relationships.2016 Pacific Business Review International.1 (3)

6. Gruji J, Moraca S and Fajsi A. Analysis of Risk Factors in the Channels of Drug Distribution: Professional Perspectives. Department of Industrial Engineering and Engineering Management, Faculty of Technical Sciences, University of Novi Sad.2020. 
7. SinghH, Majumdar A Malviva N E-PHARMACY IMPACTS ON SOCIETY AND PHARMA SECTOR IN ECONOMICAL PANDEMIC SITUATION: A REVIEW., Journal of Drug Delivery and Therapeutics. 2020

8. Blacksone EA, FuhrJP and Pociask S. The Health and Economic effects of Counterfeit Drugs.Am Health Drug Benefits.2014

9. Patil $S$ and Handa. A Counterfeit Luxury Brands Scenario in India: An Empirical Review. International Journal of Sales and Marketing, Management Research and Development.2014;4(2)

10. Chakraborty P and Dr Satsangi A. Online Pharmacy in India: A study on Digital Marketing perspective. 2019

11. Prakash $G$ and Pathak P Determinants of Counterfeit Purchase: A Study on Young Consumers in India. Journal of Scientific and Industrial Research. 26th Vol, 2017

12. Kumar R, Rakesh K, Shukla R K, Rojhe KC. Influence of Customers attitude on Purchase of Counterfeit Products in Himachal Pradesh, India. Solan. 2016

13. 13 Desai C. Online pharmacies: A boon or bane?.2016

14. Mosa ASM, Yoo I, Sheets L. A Systematic Revie of Healthcare Applications for Smartphones. BMC Medical Informatics and Decision-Making. 2012;12

15. Bian $X$ Moutinho L. Counterfeits and branded products: Effects of counterfeit ownership. Journal of Product \& Brand Management .2011;2015;379-393.

16. Zarka MM and Saleh A. Mobile Healthcare System. Catania 2016 Proceedings of International Conference for Young Researchers in Informatics, Mathematics and Engineering. 